\title{
Downregulated NORAD in neuroblastoma promotes cell proliferation via chromosomal instability and predicts poor prognosis
}

\author{
Yongbo Yu1 , Feng Chen', Yaqiong Jin'1, Yeran Yang1', Shengcai Wang', Jie Zhang'2,

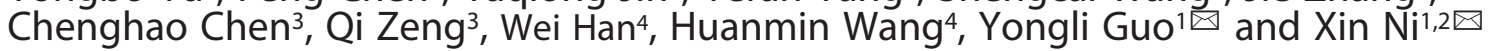

1Beijing Key Laboratory for Pediatric Diseases of Otolaryngology, Head and Neck Surgery, MOE Key Laboratory of Major Diseases in Children, Beijing Pediatric Research Institute, Beijing Children's Hospital, Capital Medical University, National Center for Children's Health (NCCH), Beijing 100045, China; 2Department of Otolaryngology, Head and Neck Surgery, Beijing Children's Hospital, Capital Medical University, National Center for Children's Health (NCCH), Beijing 100045, China; ${ }^{3}$ Department of Thoracic Surgery, Beijing Children's Hospital, Capital Medical University, National Center for Children's Health (NCCH), Beijing 100045, China; ${ }^{2}$ Department of Surgical Oncology, Beijing Children's Hospital, Capital Medical University, National Center for Children's Health (NCCH), Beijing 100045, China

Increasing evidence suggests that long non-coding RNAs (IncRNAs) are involved in neuroblastoma (NB) pathogenesis. The aim of this study was to elucidate the roles and underlying mechanism of non-coding RNA activated by DNA damage (NORAD) in childhood NB. Both public data and clinical specimens were used to determine NORAD expression. Colony formation, cell proliferation and wound healing assays were performed to evaluate NORAD effects on proliferation and migration of SH-SY5Y and SK-N-BE(2) cells. Flow cytometry was used to examine the cell cycle changes. The expression of genes and proteins involved in chromosomal instability was determined by qRT-PCR and western blotting, respectively. Our results showed that low NORAD expression correlated with advanced tumor stage, high risk and $M Y C N$ amplification in both public data and clinical samples. Kaplan-Meier analysis indicated that patients with low NORAD expression had poor survival outcomes. Functional research showed that NORAD knockdown promoted cell proliferation and migration, and arrested the cell cycle at the G2/M phase. Moreover, the expression of the DNA damage sensor, PARP1, increased after NORAD knockdown, indicating a potential contribution of NORAD to DNA damage repair. NORAD silencing also affected the expression of genes and proteins related to sister chromatid cohesion and segregation, which are involved in chromosomal instability and consequent aneuploidy. These results suggest that NORAD may serve as a tumor suppressor in NB pathogenesis and progression. Thus, NORAD is a potential therapeutic target and a promising prognostic marker for NB patients.

Key words: Neuroblastoma, long non-coding RNA, NORAD, chromosomal instability, DNA damage

Received: 18 August, 2020; revised: 16 October, 2020; accepted: 05 November, 2020; available on-line: 16 December, 2020

छe-mail: nixin@bch.com.cn (XN); guoyongli@bch.com.cn (YG) Acknowledgements of Financia Support: We appreciate the help of Professor Igor Ulitsky from the Weizmann Institute of Science, Israel. This work was supported by the National Natural Science Foundation of China (No. 81702463, 81702787), Beijing Natural Science Foundation Program and Scientific Research Key Program of Beijing Municipal Commission of Education (KZ201810025034), and Beijing Advanced Innovation Center for Big Data-Based Precision Medicine (BHME-201804).

Abbreviations: $A L K$, anaplastic lymphoma kinase; IncRNAs, long non-coding RNAs; NB, Neuroblastoma; TERT, telomerase reverse transcriptase

\section{INTRODUCTION}

Neuroblastoma (NB) in children accounts for $13 \%$ of all pediatric cancer mortality, and the 5-year overall survival rate for high-risk NB children is less than 40\% (Maris et al., 2007; Louis et al., 2015; Matthay et al., 2016). Its clinical impact and unique biology have gained attention in translational research. Although great efforts have been made by researchers and physicians, few gene alterations have been identified, such as MYCN amplification, telomerase reverse transcriptase (TERT) rearrangement, and anaplastic lymphoma kinase $(A L K)$ and ATRX mutations (Molenaar et al., 2012; Pugh et al., 2013; Peifer et al., 2015). With regard to drug discovery, only Unituxin (dinutuximab) has been approved as a novel targeted drug for NB (Bartholomew et al., 2016). Recently, chimeric antigen receptor (CAR)-modified T cell therapy has been suggested as a promising method for treating NB, but its utility and safety were still controversial during preclinical research (Kunkele et al., 2017; Richman et al., 2018). Difficulties in NB therapy emphasize the need to clarify the mechanisms underlying NB pathogenesis.

Apart from major genome aberrations, it has been shown that the tumor microenvironment, epigenetic and transcriptional regulation are also involved in NB (Domingo-Fernandez et al., 2013; Pandey et al., 2015; Borriello et al., 2016). Long non-coding RNAs (lncRNAs) are transcripts with no protein-coding ability. Functionally, lncRNAs contribute to epigenetic regulation by interacting with cellular macromolecules such as DNA, RNA and protein (Ulitsky et al., 2013; Schmitt et al., 2016). It has been reported that MEG3, HCN3 and linc01105 negatively correlate with the NB stage (Tang et al., 2016), while NBAT1 and SNHG16 control NB progression through cell proliferation and migration (Pandey et al., 2014; Yu et al., 2019). As molecular sponges, NeD125 and KCNQ1OT1 regulate $\mathrm{NB}$ apoptosis by binding to miR-125b-1 and miR-296-5p, respectively (Bevilacqua et al., 2015; Li et al., 2020). For clinical prognosis, SNHG1 has been identified as a novel predictor of high-risk NB survival (Sahu et al., 2016). These studies suggest that lncRNAs function as oncogenes and/or tumor suppressors in diverse processes in NB.

Recently, non-coding RNA activated by DNA damage (NORAD) has been found as a conserved lncRNA in the cytoplasm (Lee et al., 2016; Tichon et al., 2016; Mun- 
schauer et al., 2018). Functional studies have explored its effects in various tumor types. It has been shown that NORAD expression significantly increased in colorectal cancer (Wang et al., 2018), and promoted cell proliferation and invasion in cervical cancer (Huo et al., 2018). However, NORAD has also been reported to be a tumor suppressor that is involved in hepatocellular carcinoma via the PI3K/AKT pathway (Hu et al., 2017; Lei et al., 2018). Increasing inconsistent evidence has indicated that NORAD is involved in tumorigenesis, however, it is still unclear whether it is an oncogene or tumor suppressor in NB tumorigenesis.

To elucidate the precise function and underlying mechanism of NORAD in NB, both public data and clinical NB specimens were collected to examine its expression. Cell proliferation, colony formation and wound healing assays were performed in SH-SY5Y and SK-N-BE(2) cells to clarify NORAD function. To study the underlying mechanism of NORAD, cell cycle changes were evaluated by flow cytometry, and the expression of genes and proteins involved in chromosomal instability was determined by qRT-PCR and western blotting, respectively.

\section{MATERIALS AND METHODS}

Data processing and gene expression analysis. The Gene Expression Omnibus (GEO) public database was used to obtain gene chip and sequencing datasets on NB. Formatted family files and Series Matrix files of GSE62564 (Dataset 1: 498 cases) and GSE12460 (Dataset 2: 51 cases) were downloaded to analyze NORAD expression in NB. Clinical information of tumor stages, grades and $M Y C N$ status was picked out from items in these files. Based on the survival data in Dataset 1 , the prognostic value of NORAD was evaluated by KaplanMeier survival analysis (https://www.ncbi.nlm.nih.gov/ geo $/$ query $/$ acc.cgi? acc=GSE62564). Patients were divided into low-expression (249 cases) and high-expression (249 cases) groups based on the median expression of NORAD.

Clinical specimens and cell lines. To verify NORAD expression in NB, $40 \mathrm{NB}$ tumor specimens stored in liquid nitrogen were obtained from Beijing Biobank for Diseases in Children, Beijing Children's Hospital. All the samples in this biobank were collected along with signed informed consents. Clinical staging information was provided by the Pathology Department, based on the International Neuroblastoma Staging System (INSS). The Ethics Committees of Beijing Children's Hospital approved this study (2018-143). The SHSY5Y and SK-N-BE(2) cell lines were purchased from American Type Culture Collection (Manassas, VA, USA). The cells were cultured in DMEM containing 10\% fetal bovine serum (FBS) and maintained in a humidified incubator $\left(5 \% \mathrm{CO}_{2}, 37^{\circ} \mathrm{C}\right)$.

RNA extraction and qRT-PCR assays. Tumor RNA was extracted using an RNA isolation kit (Zymo Research, USA) after tissues were homogenized in TRIzol reagent (Invitrogen, Carlsbad, CA, USA). A First Strand cDNA Synthesis Kit (Invitrogen) was used for RNA reverse transcription. SYBR Green Master mix was applied to detect gene expression using ViiA7 Dx machine (Applied Biosystems, USA). The primer sequences for target genes and reference genes were listed in Supplementary Table 1 . The relative expression of RNAs was calculated using the $2^{-\Delta \mathrm{Ct}}$ method.

Cell transfection. For cell transfection assays, the siRNA oligonucleotides for NORAD and negative con- trol were synthesized by Sangon Biotech (Shanghai, China). These siRNAs were termed siRNA1\#, siRNA2\# and siNC, respectively. siRNA (100 nM) was transfected into cells using Lipofectamine RNAiMAX (Invitrogen). A series of experiments were performed after the medium was replaced with normal culture medium $8 \mathrm{~h}$ after the transfection. The following siRNA sequences used were: NORAD: siRNA1\#, 5'-UAGCCCUUCUAGAUGGAAAdTdT-3' and siRNA2\#, 5'-CCACUGGCUGUGCCCAGACdTdT-3'; negative control (5'-UUCUCCGAACGUGUCACGUdTdT-3'.

Cell proliferation assay. Cell proliferation was monitored by a cell kinetic analyzer (ACEA, Biosciences, USA) as described previously (Yu et al., 2018). Briefly, about $2 \times 10^{3}$ cells were seeded into an E-plate, incubated at $37^{\circ} \mathrm{C}$ for $24 \mathrm{~h}$, transfected with siRNA and cultured for 3 days. Data analysis was finally performed by the preinstalled software.

Colony formation assay. A total of $1 \times 10^{3}$ cells per well were plated into 6-well plates and transfected with siRNA. The medium was replaced every 3 days. Ten days later, 4\% paraformaldehyde (Sigma-Aldrich, St. Louis, MO, USA) and $0.1 \%$ crystal violet (SigmaAldrich) were used to fix and stain the cells for $10 \mathrm{~min}$, respectively. Cell colonies were observed using a light microscope (IX73; Olympus, Japan).

Wound healing assay. Cells were plated into 6-well plates at $3 \times 10^{5}$ cells per well. A "wound" was created with a micropipette tip when the cells reached about $50 \%$ confluence. The detached cells were gently removed with PBS and the attached cells were transfected with siRNA. The wound was observed and photographed by a light microscope at 0, 24, 48 and $72 \mathrm{~h}$. AlphaView SA 3.4.0 (ProteinSimple, USA) was used to measure the wound width.

DNA damage and cell cycle analysis. To verify the role of NORAD in DNA damage, cells were exposed to doxorubicin $(0.25 \mathrm{mM}, 0.5 \mathrm{mM}, 1 \mathrm{mM}$; Sigma-Aldrich) for $24 \mathrm{~h}$ and NORAD expression was determined by qRT-PCR. The level of DNA damage sensor, poly (ADP-ribose) polymerase 1 (PARP1), was examined $48 \mathrm{~h}$ after NORAD silencing. For cell cycle analysis, SH-SY5Y cells were transfected with siRNAs, incubated for $72 \mathrm{~h}$, and then collected and resuspended in cold ethanol $(70 \%)$ overnight at $4^{\circ} \mathrm{C}$. The cells were pelleted and then incubated with working solution $[2 \% \mathrm{FBS}, 10$ $\mu \mathrm{L}$ propidium iodide $(1 \mathrm{mg} / \mathrm{mL}$, Sigma-Aldrich) and 2 $\mu \mathrm{L}$ RNase A $(10 \mathrm{mg} / \mathrm{mL}$, TIANGEN, China)] for 30 min at $37^{\circ} \mathrm{C}$ in the dark. The cell cycle was evaluated using a flow cytometer (FACSCalibur, BD, USA). At least $1 \times 10^{4}$ cells were analyzed for each sample.

Western blotting. After transfection with siRNA, the cells were incubated for $72 \mathrm{~h}$, harvested and lysed with cold RIPA buffer for $30 \mathrm{~min}$ on ice. Bicinchoninic acid (BCA) protein assay (Pierce, USA) was used to de-

Table 1. Cell cycle arrest of SH-SY5Y cells after siRNA transfection.

\begin{tabular}{llll}
\hline \multirow{2}{*}{ Groups } & \multicolumn{3}{l}{ Distribution of cell cycle } \\
\cline { 2 - 4 } & G0/G1 & $\mathrm{S}$ & $\mathrm{G} 2 / \mathrm{M}$ \\
\hline siNC & $59.7 \pm 2.43$ & $27.2 \pm 3.42$ & $13.1 \pm 1.10$ \\
\hdashline siRNA1\# & $49.8 \pm 1.48^{*}$ & $30.1 \pm 0.43$ & $20.1 \pm 1.90^{*}$ \\
\hline siRNA2\# & $50.4 \pm 2.11^{*}$ & $31.3 \pm 0.94$ & $18.3 \pm 0.82^{*}$ \\
\hline
\end{tabular}

Data are expressed as means \pm S.D. from three independent experiments $\left({ }^{*} p<0.05\right)$. 

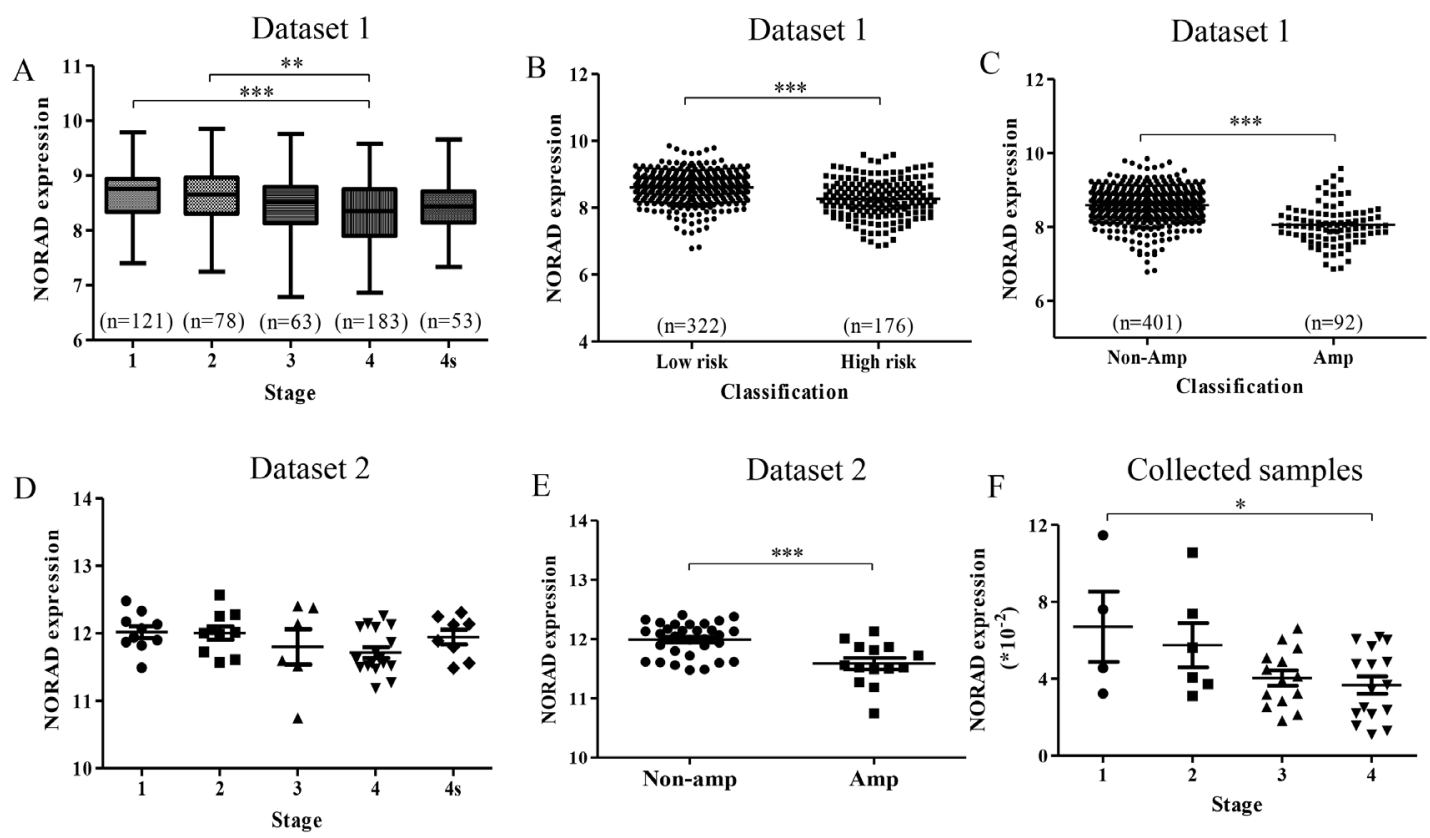

Figure 1. NORAD expression negatively correlates with clinical characteristics of NB tumor.

(A-C) NORAD expression in different NB risk groups, stages and MYCN status in Dataset 1. (D and E) NORAD expression in different stages and MYCN status in Dataset 2. (F) NORAD expression was downregulated in higher clinical stages of the collected NB tumors. ${ }^{*} p<0.05$, ${ }^{* *} p<0.01,{ }^{* * *} p<0.001$.

termine protein concentration. Each protein sample $(20$ $\mu \mathrm{g})$ was separated by SDS-PAGE and electrophoretically transferred to a nitrocellulose filter membrane (PALL, USA). Non-fat milk (5\%) was used to block the membranes, which were subsequently incubated with the following primary antibodies overnight at $4^{\circ} \mathrm{C}$ : CDK1 (Abcam, Cambridge, UK; 1:5000), SMC3 (Abcam; 1:1000), Aurora B (Abcam; 1:10000), CENPA (Abcam; 1:1000) and GAPDH (Abcam; 1:1000). After incubation with secondary antibodies (IR800-IRDye $\mathbb{8} 800$, Abcam; 1:5000), the membranes were scanned using the Odyssey CLx system, and relative densitometric analysis was performed using ImageJ software.

Statistical analysis. All graphs were generated using GraphPad Prism 5.0. The $t$-test was performed to analyze the differences between two groups. Multiple comparisons were assessed by one-way ANOVA. Kaplan-Meier survival analysis was used to evaluate prognosis. $p<0.05$ was set as statistically significant. All the results were expressed as means \pm standard deviations (S.D.).

\section{RESULTS}

\section{NORAD expression negatively correlates with the clinical characteristics of NB}

Based on stratification of tumor stage, risk group and MYCN status in public GEO Dataset 1 (GSE62564: 498 cases), we found that NORAD expression gradually decreased with the increase in tumor stage (Fig. 1A). Additionally, NORAD was downregulated in the highrisk NB (Fig. 1B) and $M Y C N$ amplification groups (Fig. 1C). Independent Dataset 2 (GSE12460: 51 cases) further confirmed the downregulation tendency of NO$\mathrm{R} A D$ (Fig. 1D and $\mathrm{E}$ ). To further validate the results, we measured the NORAD expression level in $40 \mathrm{NB}$ tissues and found that it was downregulated with the increase in tumor stage (Fig. 1F). These findings firmly indicated that NORAD expression negatively correlates with NB progression.

\section{NORAD silencing promotes cell proliferation}

The effects of NORAD on cell proliferation were assessed in SH-SY5Y and SK-N-BE(2) cells. We first confirmed that siRNAs could effectively silence NORAD expression (Fig. 2A). Furthermore, cell growth was significantly elevated when NORAD was silenced (Fig. 2B and $\mathrm{C}$ ). Consistent with this finding, the colony formation assay showed that NORAD knockdown promoted colony formation both in number and in size (Fig. 2D). Therefore, we speculated that NORAD downregulation promotes cell proliferation of NB cells.

\section{NORAD silencing promotes cell migration}

The NORAD effects on cell migration were examined by the wound healing assay. The micropipette tip-made "Gap" represents a "wound", and a decrease in the width of the "Gap" indicates cell migration. As shown in Fig. 3A and B, the "Gap" width in the NO$\mathrm{R} A D$ silencing group decreased faster compared to the control group, suggesting that NORAD knockdown significantly increased the cell migration ability. Quantification analysis further confirmed that the difference in the "Gap" width between the NORAD silencing groups and the control group was statistically significant (Fig. 3C and D).

\section{NORAD silencing induces cell cycle arrest}

NORAD is a non-coding RNA activated by DNA damage and we confirmed that NORAD was activated by doxorubicin-induced DNA damage (Fig. 4A). Moreover, the expression of PARP1, which is a DNA damage sensor, increased after NORAD silencing, suggesting that NORAD contributes to DNA damage repair (Fig. 4B). DNA damage is closely associated with 

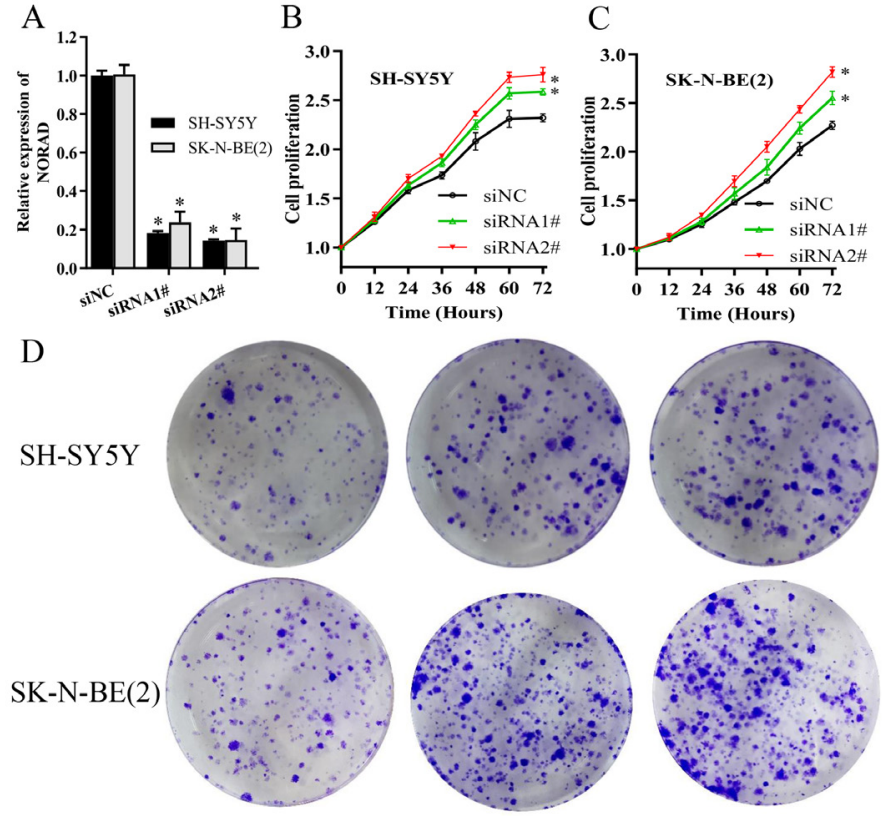

$\operatorname{sinC}$
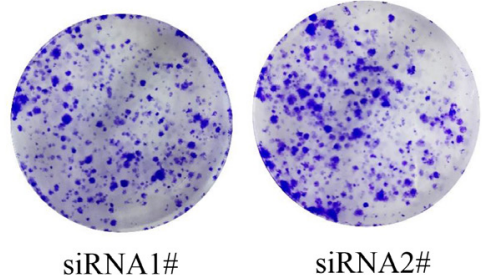

Figure 2. NORAD silencing promotes cell proliferation of SH-SY5Y and SK-N-BE(2) cells.

(A) Validation of NORAD knockdown by siRNAs. (B, C) Cell proliferation of SH-SY5Y (B) and SK-N-BE(2) cells (C). (D) Representative photographs of SH-SY5Y and SK-N-BE(2) colonies. ${ }^{*} p<0.05$ vs control.
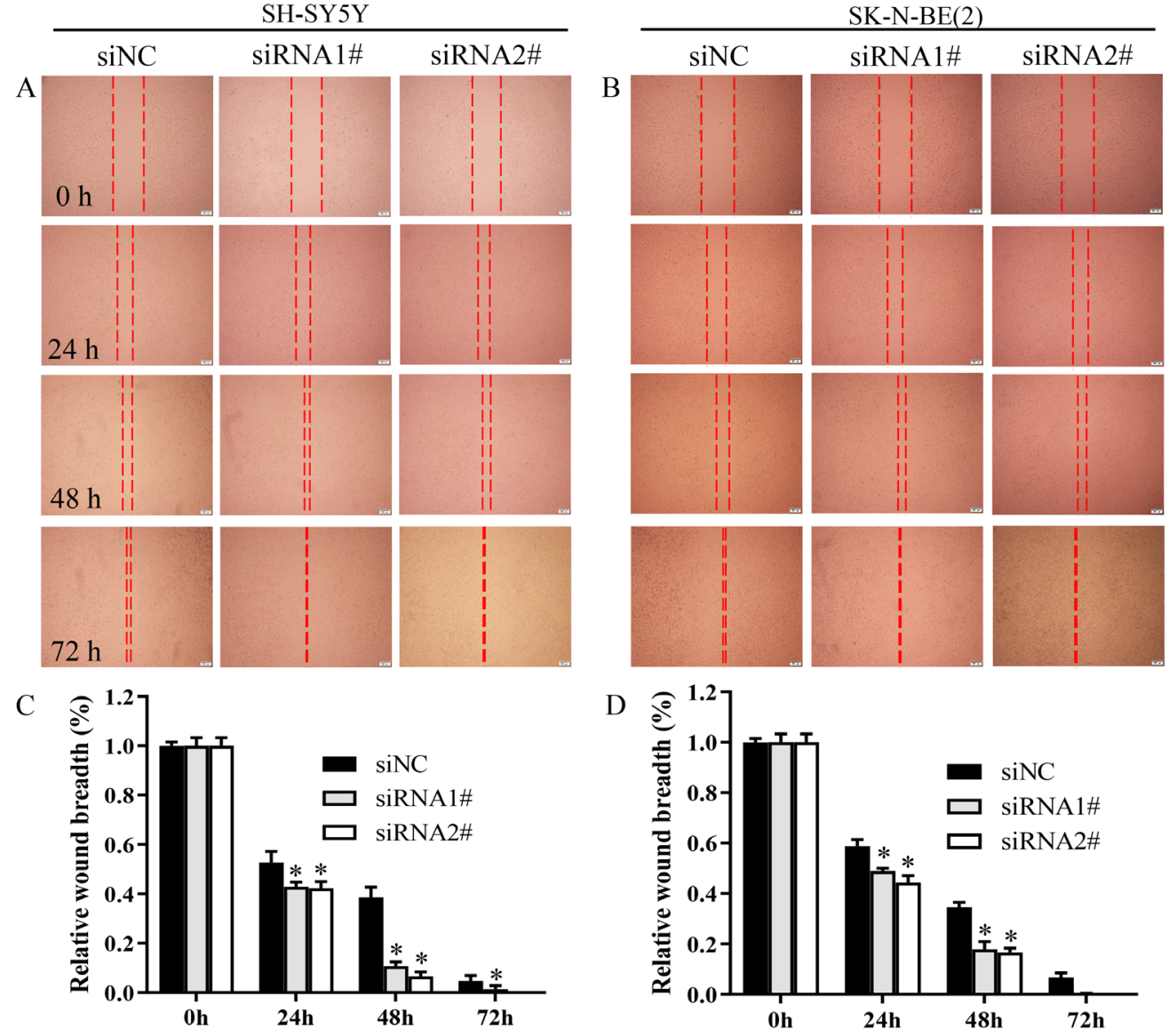

Figure 3. NORAD silencing promotes cell migration of SH-SY5Y and SK-N-BE(2) cells.

(A, B) Representative wound healing images of SH-SY5Y (A) and SK-N-BE(2) cells (B) captured at 0, 24, 48 and 72 h. (C, D) Quantification of the wound width at the indicated time points with SH-SY5Y (C) and SK-N-BE(2) (D) cells. Scale bar: $200 \mu$ m. ${ }^{*} p<0.05$ vs control. 


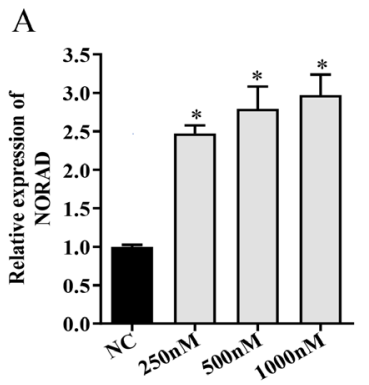

C

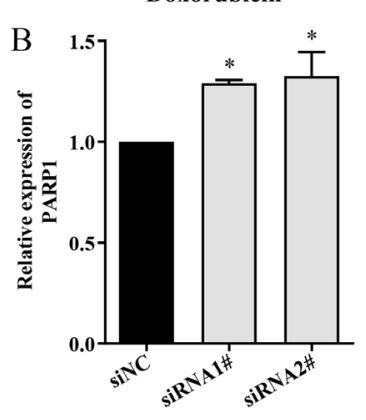

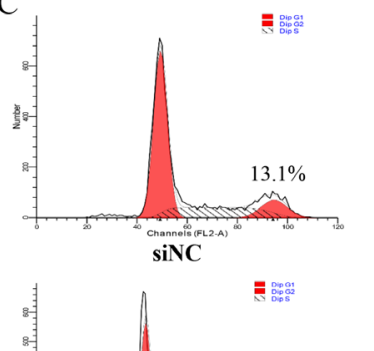

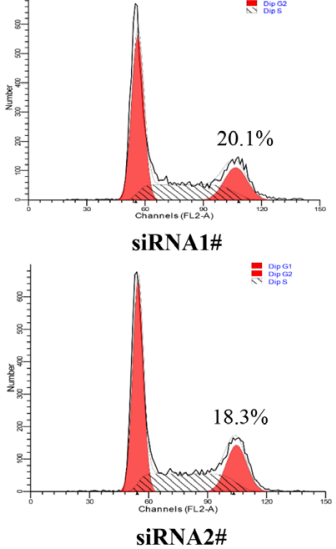

$\mathrm{D}$

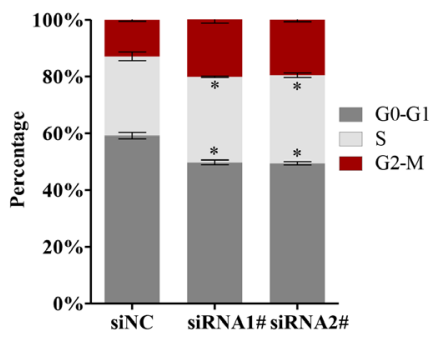

$\mathrm{E}$

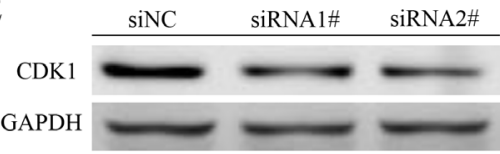

F
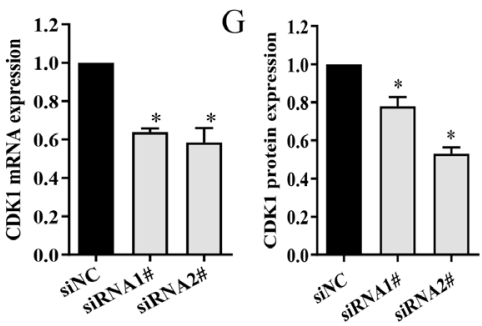

Figure 4. DNA damage and cell cycle delay after NORAD silencing in SH-SY5Y cells.

(A) Doxorubicin $(0.25,0.5$ and $1 \mathrm{mM})$ stimulated NORAD expression in a dose-dependent manner. (B) The DNA damage sensor, PARP1, was elevated after NORAD silencing. (C) Flow cytometry was used to determine cell cycle changes, which were quantified (D), showing that the percentage of cells in the G2/M phase increased after NORAD silencing. (E-G) The mRNA and protein expression level of CDK1 was downregulated after NORAD silencing in SH-SY5Y cells. ${ }^{*} p<0.05$ vs control.

the cell cycle, thus we examined the effect of NORAD on the cell cycle by flow cytometry (Fig. 4C). As shown in Fig. 4D and Table 1, the number of cells in the G0/G1 phase declined, while the number of cells in the $\mathrm{G} 2 / \mathrm{M}$ phase increased after NORAD knockdown. Cyclin-dependent kinase 1 (CDK1) is a critical player in promoting $\mathrm{G} 2 / \mathrm{M}$ transition. We found that NORAD knockdown downregulated CDK1 at the mRNA and protein level, further confirming cell cycle arrest at G2/M in SH-SY5Y cells (Fig. 4E-G).

\section{NORAD silencing impairs sister chromatid cohesion and segregation}

Sister chromatid cohesion and segregation are critical events for maintaining chromosomal stability in response to DNA damage. We examined the genes and proteins involved in these processes. As shown in Fig. $5 \mathrm{~A}$, the sister chromatid cohesion-related genes: structural maintenance of chromosomes $1 \mathrm{~A}$ (SMC1A), cohesin complex component (RAD21), extra spindle pole bodies like 1 (ESPL1) and polo-like kinase 1 (PLK1),
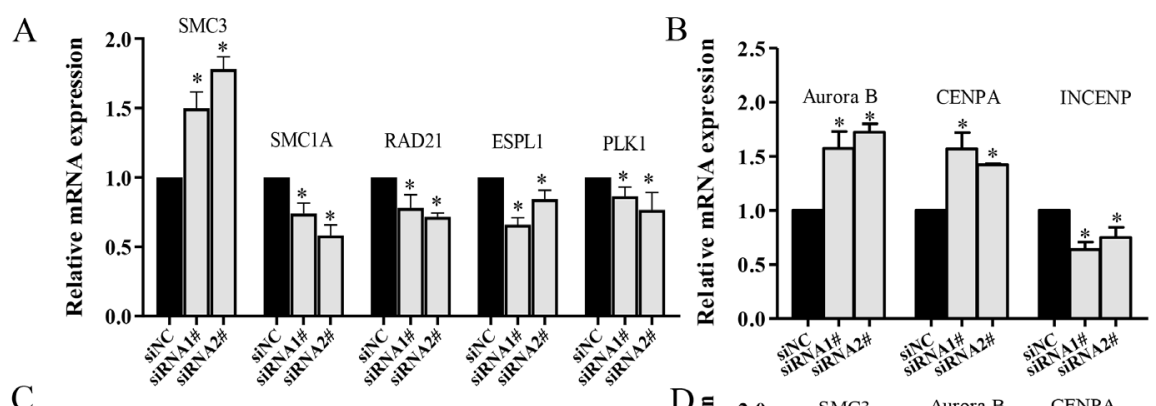

$\mathrm{C}$
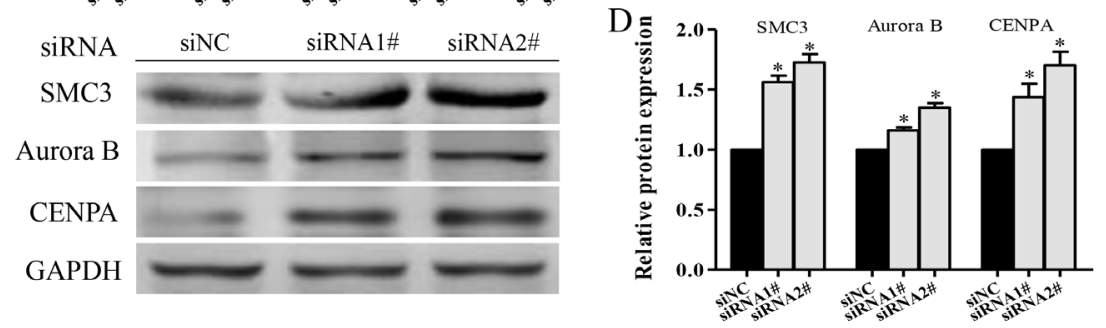

Figure 5. Impairment of sister chromatid cohesion and segregation is induced by NORAD silencing.

(A) mRNA expression of sister chromatid cohesion-related genes and (B) sister chromatid segregation-related genes in cells transfected with siRNAs. (C) Protein expression of SMC3, Aurora B and CENPA measured by western blotting and (D) relative densitometric analysis of the protein bands. ${ }^{*} p<0.05$ vs control. 

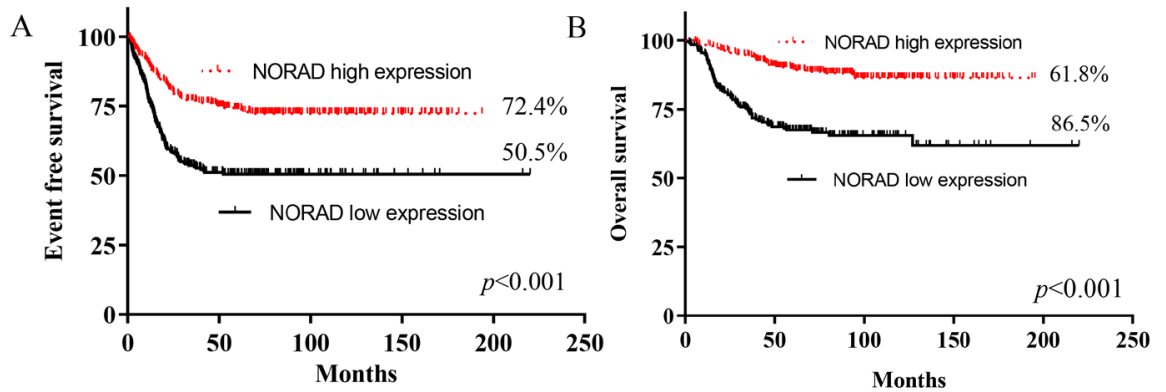

Figure 6. Kaplan-Meier survival analysis for NB patients in GSE62564 dataset.

The Kaplan-Meier curves for (A) event-free survival (EFS) and (B) overall survival (OS) of NB patients with low NORAD expression versus high NORAD expression. The $p$-values were obtained by the log-rank test. $p<0.001$.

were suppressed after NORAD silencing, while SMC3 was significantly upregulated. Chromosomal passenger complex (CPC) is related to chromosome separation; our results demonstrated that the $\mathrm{CPC}$ component genes, Aurora $B$ and centromere protein A (CENPA), were upregulated upon NORAD silencing, while inner centromere protein (INCENP) was downregulated (Fig. $5 \mathrm{~B})$. The protein expression for the key genes was examined to confirm the deregulation of sister chromatid cohesion and segregation after NORAD knockdown (Fig. 5C and D).

\section{High NORAD expression is critical for patient survival}

To explore the prognostic value of NORAD, patients in Dataset 1 were divided into two groups according to the median expression of NORAD: high expression group (249 cases) and low expression group (249 cases). Kaplan-Meier survival analysis was performed to analyze event-free survival (EFS) and overall survival (OS). The results showed that the EFS was $50.5 \%$ and $72.4 \%$ in low- and high-expression group, respectively, and the OS was $61.8 \%$ and $86.5 \%$, respectively (Fig. 6A and B), indicating that patients with low NORAD expression had poorer EFS and OS than patients with high NORAD expression. These results suggest that $N O R A D$ is a potential prognostic marker for NB patients.

\section{DISCUSSION}

In children, NB is the most common solid tumor, but NB pathogenesis still has not been comprehensively understood after decades of research efforts. Genome instability is the most marked characteristic of cancer and recently lncRNAs, such as CCAT2, TERRA and NORAD, have been demonstrated to be involved in genome regulation (Ling et al., 2013; Cusanelli et al., 2015; Lee et al., 2016). As a novel cytoplasmic noncoding RNA, NORAD has been reported to preserve genome stability in human cells, but its effects and molecular mechanism in NB are unknown (Lee et al., 2016, Munschauer, Nguyen et al. 2018). In the present study, we found that NORAD was downregulated in $\mathrm{NB}$; this downregulation promoted cell proliferation of cell lines via chromosomal instability and predicted poor prognosis.

Deregulated gene expression is involved in tumorigenesis. Previous studies have explored genome-scale transcriptional alterations in NB by microarray and RNA-sequencing (Wang et al., 2014; Henrich et al., 2016). Herein, we found that NORAD expression negatively correlated with the NB stage and was downreg- ulated in both high-risk and MYCN-amplified NB (Fig. 1A-C). Independent Dataset 2 (GSE12460) and clinical samples further validated our results (Fig. 1D-F). Consistent with our findings, low NORAD expression has been also observed in colon cancer and hepatocellular carcinoma (Hu et al., 2017; Lei et al., 2018). Decreased NORAD expression in tumors suggests it may be a tumor suppressor (Ventura 2016), but this speculation has not been confirmed in detail. Additionally, it has been reported that NORAD was highly expressed and played oncogenic roles in esophageal squamous cell carcinoma (Huo et al., 2018; Sun et al., 2018; Wang et al., 2018). Tumor type-dependent expression of NO$\mathrm{R} A D$ makes its function and mechanism more complex to elucidate, thus it is still unclear whether $N O R A D$ is involved in NB tumorigenesis.

Previous studies have demonstrated that NORAD promoted tumor cell proliferation and invasion, and epithelial-mesenchymal transition (EMT) (Huo et al., 2018; Kawasaki et al., 2018). To clarify the effects of NOR AD in NB, functional studies were performed. NORAD silencing significantly stimulated cell proliferation and migration of SH-SY5Y and SK-N-BE(2) cells (Figs. 2 and 3), which is in line with the finding that NB with downregulated NORAD showed high tumor stage and risk. Taken together, the results from the public datasets, clinical validation and in vitro study verified that $N O R A D$ acts as a tumor suppressor in $\mathrm{NB}$ progression.

Tumor cell proliferation is associated with various biological processes, such as cell death, apoptosis, cell cycle and DNA damage (Hanahan et al., 2011). Our results showed that NORAD expression was significantly increased in a dose-dependent manner upon DNA damage by doxorubicin in SH-SY5Y cells (Fig. 4A). However, whether NORAD plays a role in DNA damage promotion or DNA damage repair has not been reported. With regard to this issue, the DNA damage sensor, PARP1, was examined. As PARP1 can recognize DNA breaks and serves as a scaffold for early recruitment of repair proteins to facilitate DNA repair (Wei et al., 2016; Ray Chaudhuri et al., 2017), the elevation in PARP1 expression after NORAD knockdown suggests that NORAD contributes to DNA damage repair (Fig. 4B). Generally, cell cycle checkpoints arrest the cell cycle to maintain genome stability in response to cellular DNA damage (Malumbres et al., 2009; Uryga et al., 2016). Our data showed that the cell number in the G0/G1 phase declined, whereas it increased in the G2/M phase after NORAD knockdown (Fig. 4C and D). Moreover, CDK1, which is a critical player in promoting G2/M transition (Otto et al., 2017), was significantly downregulated at the mRNA and protein level 
(Fig. 4E and F). Cell cycle delay provides more time for DNA damage repair and reduces gene alterations. Our results indicated that NORAD silencing induced DNA damage and cell cycle arrest at the G2/M transition. These findings establish the functional relevance of NORAD in DNA damage and G2/M phase arrest, however, the underlying molecular mechanism remains unclear.

During the G2/M phase transition, sister chromatid cohesion and accurate chromosome segregation are pivotal mechanisms safeguarding genome stability and mitotic processes (M phase) (Makrantoni et al., 2018). Recently, NORAD has been reported to assemble a topoisomerase complex by interacting with RNA-binding motif protein X-linked (RBMX), and to function as a potent molecular decoy for PUMILIO proteins. Both RBMX and PUMILIO proteins are cohesion regulators that maintain proper cohesion of sister chromatids (Matsunaga et al., 2012; Lee et al., 2016, Munschauer et al., 2018). Herein, we demonstrated that NORAD silencing triggered CIN by interfering with sister chromatid cohesion and chromosome segregation during mitosis. We found that the expression of $S M C 1 A$, RAD21, ESPL1 and PLK1 was remarkably suppressed after $N O R A D$ silencing, while SMC3 was significantly increased (Fig. 5A, C and D). These genes are components of cohesin and associated regulators. Cohesin complex forms a ring-shaped molecule to entrap sister DNA molecules together until the onset of anaphase (Peters et al., 2012). The core of this ring is composed of SMC1, SMC3 and the kleisin subunit, RAD21 (Eichinger et al., 2013). The connection is cleaved and released by ESPL1 and PLK1, thereby initiating further chromosome segregation (Losada, 2014). Herein, the downregulation of cohesion-related proteins may render the cohesin ring less condensed and the cohesion process instable, which may cause subsequent dysfunction of chromosome segregation.

Chromosome segregation involves the partitioning of genomic material during metaphase and anaphase, which is dependent on highly conserved CPC. Our results showed that the level of CPC-related genes, $A u$ rora $B$ and $C E N P A$, was increased, while for INCENP it was decreased after NORAD silencing (Fig. 5B-D). Although it is unclear how NORAD regulates CPC-related genes, the fact that it controls centromere components by sequestering PUMILIO may account for this regulation to some extent (Lee et al., 2016). CPC cellular localization is dynamic during the cell cycle and regulates the mitotic process (Carmena et al., 2012). It has a central role in the regulation of kinetochoremicrotubule attachments, and it controls the correct alignment of chromosomes on the spindle equator. The CPC translocates to the spindle midzone in anaphase and facilitates the movement of sister chromatids to the opposite poles (Ruchaud et al., 2007). In the present study, deregulated expression of the CPC component proteins suggested potential defects in chromosome segregation. A previous study has reported that NORAD inactivation induced anaphase bridges and mitotic slippage (Lee et al., 2016), which further supports our hypothesis.

Defects in sister chromatid cohesion and deregulated separation are involved in CIN and consequent aneuploidy. These events are characteristic features of human malignancies and have been proposed as important drivers of tumor formation and progression (Hanahan \& Weinberg, 2011). NORAD inactivation has been previously reported to cause CIN and aneuploidy (Lee et al., 2016). Accordingly, NORAD downregulationinduced genetic instability may account for NB tumor initiation, progression and poor outcome.

In conclusion, we demonstrated that $N O R A D$ is significantly downregulated in NB with high risk or high tumor stage. Clinically, patients with low NO$\mathrm{R} A D$ expression had a worse survival outcome than patients with high NORAD expression. Our functional study showed that $N O R A D$ silencing promoted cell proliferation, migration and $\mathrm{G} 2 / \mathrm{M}$ cell cycle arrest. The underlying mechanism studies verified that NO$\mathrm{R} A D$ silencing caused defects in both sister chromatid cohesion and accurate separation, which are involved in DNA damage. Our results suggest that NORAD contributes to NB pathogenesis and progression by modulating sister chromatid cohesion and separation. NORAD is thus a potential therapeutic target and a promising prognostic marker for NB patients. This study demonstrated that lncRNA-mediated genome instability is involved in the regulation of NB development.

\section{Authors' contributions}

$\mathrm{XN}$ and YLG designed the study and critically revised the paper; YBY performed the experiments and wrote the manuscript; SCW, JZ, CHC, WH, HMW and QZ contributed to patient recruitment and tumor tissue collection; YQJ and YRY performed the bioinformatic analysis; FC cultured cells and conducted the statistical analysis. All authors read and approved the final manuscript.

\section{Declaration of conflict of interests}

The authors declare they have no actual or potential competing financial interests.

\section{REFERENCES}

Bartholomew J, Washington T, Bergeron S, Nielson D, Saggio J, Quirk L (2016) Dinutuximab: a novel immunotherapy in the treatment of pediatric patients with high-risk neuroblastoma. I Pediatr Oncol Nurs 34: 5-12. https://doi.org/10.1177/1043454216659448

Bevilacqua V, Gioia U, Di Carlo V, Tortorelli AF, Colombo T, Bozzoni I, Laneve P, Caffarelli E (2015) Identification of linc-NeD125, a novel long non coding RNA that hosts miR-125b-1 and negatively controls proliferation of human neuroblastoma cells. RNA Biol 12: 1323-1337. https://doi.org/10.1080/15476286.2015.1096488

Borriello L, Seeger RC, Asgharzadeh S, DeClerck YA (2016) More than the genes, the tumor microenvironment in neuroblastoma. Cancer Lett 380: 304-314. https://doi.org/10.1016/j.canlet.2015.11.017

Carmena M, Wheelock M, Funabiki H, Earnshaw WC (2012) The chromosomal passenger complex (CPC): from easy rider to the godfather of mitosis. Nat Rev Mol Cell Biol 13: 789-803. https://doi. $\operatorname{org} / 10.1038 / \mathrm{nrm} 3474$

Cusanelli E, Chartrand P (2015) Telomeric repeat-containing RNA TERRA: a noncoding RNA connecting telomere biology to genome integrity. Front Genet 6: 143. https://doi.org/10.3389/ fgene.2015.00143

Domingo-Fernandez R, Watters K, Piskareva O, Stallings RL, Bray I (2013) The role of genetic and epigenetic alterations in neuroblastoma disease pathogenesis. Pediatr Surg Int 29: 101-119. https://doi. org/10.1007/s00383-012-3239-7

Eichinger CS, Kurze A, Oliveira RA, Nasmyth K (2013) Disengaging the Smc3/kleisin interface releases cohesin from Drosophila chromosomes during interphase and mitosis. EMBO J 32: 656-665. https://doi.org/10.1038/emboj.2012.346

Hanahan D, Weinberg RA (2011) Hallmarks of cancer: the next generation. Cell 144: 646-674. https://doi.org/10.1016/j.cell.2011.02.013

Henrich KO, Bender S, Saadati M, Dreidax D, Gartlgruber M, Shao C, Herrmann C, Wiesenfarth M, Parzonka M, Wehrmann L, Fischer M, Duffy DJ, Bell E, Torkov A, Schmezer P, Plass C, Hofer T, Benner A, Pfister SM, Westermann F (2016) Integrative genomescale analysis identifies epigenetic mechanisms of transcriptional deregulation in unfavorable neuroblastomas. Cancer Res 76: 5523-5537. https://doi.org/10.1158/0008-5472.CAN-15-2507 
Hu B, Cai H, Zheng R, Yang S, Zhou Z, Tu J (2017) Long non-coding RNA 657 suppresses hepatocellular carcinoma cell growth by acting as a molecular sponge of miR-106a-5p to regulate PTEN expression. Int J Biochem Cell Biol 92: 34-42. https://doi.org/10.1016/j. biocel.2017.09.008

Huo H, Tian J, Wang R, Li Y, Qu C, Wang N (2018) Long noncoding RNA NORAD upregulate SIP1 expression to promote cell proliferation and invasion in cervical cancer. Biomed Pharmacother 106: 1454-1460. https://doi.org/10.1016/j.biopha.2018.07.101

Kawasaki N, Miwa T, Hokari S, Sakurai T, Ohmori K, Miyauchi K, Miyazono K, Koinuma D (2018) Long noncoding RNA NORAD regulates transforming growth factor-beta signaling and epithelial-tomesenchymal transition-like phenotype. Cancer Sci 109: 2211-2220. https://doi.org/10.1111/cas.13626

Kunkele A, Taraseviciute A, Finn LS, Johnson AJ, Berger C, Finney O, Chang CA, Rolczynski LS, Brown C, Mgebroff S, Berger M, Park JR, Jensen MC (2017) Preclinical assessment of CD171-directed CAR T-cell adoptive therapy for childhood neuroblastoma: CE7 epitope target safety and product manufacturing feasibility. Clin Cancer Res 23: 466-477. https://doi.org/10.1158/1078-0432.CCR$16-0354$

Lee S, Kopp F, Chang TC, Sataluri A, Chen B, Sivakumar S, Yu H, Xie Y, Mendell JT (2016) Noncoding RNA NORAD regulates genomic stability by sequestering PUMILIO proteins. Cell 164: 6980. https://doi.org/10.1016/i.cell.2015.12.017

Lei Y, Wang YH, Wang XF, Bai J (2018) LINC00657 promotes the development of colon cancer by activating PI3K/AKT pathway. Eur Rev Med Pharmacol Sci 22: 6315-6323. https://doi.org/10.26355/ eurrev 20181016042

Li MM, Liu XH, Zhao YC, Ma XY, Zhou YC, Zhao YX, Liu XY (2020) Long noncoding RNA KCNQ1OT1 promotes apoptosis in neuroblastoma cells by regulating miR-296-5p/Bax axis. FEBS $J$ 287: 561-577. https://doi.org/10.1111/febs.15047

Ling H, Spizzo R, Atlasi Y, Nicoloso M, Shimizu M, Redis RS, Nishida N, Gafa R, Song J, Guo Z, Ivan C, Barbarotto E, De Vries I, Zhang X, Ferracin M, Churchman M, van Galen JF, Beverloo BH, Shariati M, Haderk F, Estecio MR, Garcia-Manero G, Patijn GA, Gotley DC, Bhardwaj V, Shureiqi I, Sen S, Multani AS, Welsh J, Yamamoto K, Taniguchi I, Song MA, Gallinger S, Casey G, Thibodeau SN, Le Marchand L, Tiirikainen M, Mani SA, Zhang W, Davuluri RV, Mimori K, Mori M, Sieuwerts AM, Martens JW, Tomlinson I, Negrini M, Berindan-Neagoe I, Foekens JA, Hamilton SR, Lanza G, Kopetz S, Fodde R, Calin GA (2013) CCAT2, a novel noncoding RNA mapping to 8q24, underlies metastatic progression and chromosomal instability in colon cancer. Genome Res 23: 14461461. https://doi.org/10.1101/gr.152942.112

Losada A (2014) Cohesin in cancer: chromosome segregation and beyond. Nat Rev Cancer 14: 389-393. https://doi.org/10.1038/nrc3743

Louis CU, Shohet JM (2015) Neuroblastoma: molecular pathogenesis and therapy. Annu Rev Med 66: 49-63. https://doi.org/10.1146/ annurev-med-011514-023121

Makrantoni V, Marston AL (2018) Cohesin and chromosome segregation. Curr Biol 28: R688-R693. https://doi.org/10.1016/j. cub.2018.05.019

Malumbres M, Barbacid M (2009) Cell cycle, CDKs and cancer: a changing paradigm. Nat Rev Cancer 9: 153-166. https://doi. org/10.1038/nrc2602

Maris JM, Hogarty MD, Bagatell R, Cohn SL (2007) Neuroblastoma. Lancet 369: 2106-2120. https://doi.org/10.1016/s01406736(07)60983-0

Matsunaga S, Takata H, Morimoto A, Hayashihara K, Higashi T, Akatsuchi K, Mizusawa E, Yamakawa M, Ashida M, Matsunaga TM, Azuma T, Uchiyama S, Fukui K (2012) RBMX: a regulator for maintenance and centromeric protection of sister chromatid cohesion. Cell Rep 1: 299-308. https:/ /doi.org/10.1016/j.celrep.2012.02.005

Matthay KK, Maris JM, Schleiermacher G, Nakagawara A, Mackall CL, Diller L, Weiss WA (2016) Neuroblastoma. Nat Rev Dis Primers 2: 16078. https://doi.org/10.1038/nrdp.2016.78

Molenaar JJ, Koster J, Zwijnenburg DA, van Sluis P, Valentijn LJ, van der Ploeg I, Hamdi M, van Nes J, Westerman BA, van Arkel J, Ebus ME, Haneveld F, Lakeman A, Schild L, Molenaar P, Stroeken $\mathrm{P}$, van Noesel MM, Ora I, Santo EE, Caron HN, Westerhout EM, Versteeg R (2012) Sequencing of neuroblastoma identifies chromothripsis and defects in neuritogenesis genes. Nature 483: 589-593. https://doi.org/10.1038/nature10910

Munschauer M, Nguyen CT, Sirokman K, Hartigan CR, Hogstrom L, Engreitz JM, Ulirsch JC, Fulco CP, Subramanian V, Chen J, Schenone M, Guttman M, Carr SA, Lander ES (2018) The NORAD lncRNA assembles a topoisomerase complex critical for genome stability. Nature 561: 132-136. https://doi.org/10.1038/s41586-018$0453-z$

Otto T, Sicinski P (2017) Cell cycle proteins as promising targets in cancer therapy. Nat Rev Cancer 17: 93-115. https://doi.org/10.1038/ nrc. 2016.138
Pandey GK, Kanduri C (2015) Long noncoding RNAs and neuroblastoma. Oncotarget 6: 18265-18275. https://doi.org/10.18632/oncotarget. 4251

Pandey GK, Mitra S, Subhash S, Hertwig F, Kanduri M, Mishra K, Fransson S, Ganeshram A, Mondal T, Bandaru S, Ostensson M, Akyurek LM, Abrahamsson J, Pfeifer S, Larsson E, Shi L, Peng Z, Fischer M, Martinsson T, Hedborg F, Kogner P, Kanduri C (2014) The risk-associated long noncoding RNA NBAT-1 controls neuroblastoma progression by regulating cell proliferation and neuronal differentiation. Cancer Cell 26: 722-737. https://doi.org/10.1016/j. ccell.2014.09.014

Peifer M, Hertwig F, Roels F, Dreidax D, Gartlgruber M, Menon R, Kramer A, Roncaioli JL, Sand F, Heuckmann JM, Ikram F, Schmidt R, Ackermann S, Engesser A, Kahlert Y, Vogel W, Altmuller J, Nurnberg P, Thierry-Mieg J, Thierry-Mieg D, Mariappan A, Heynck S, Mariotti E, Henrich KO, Gloeckner C, Bosco G, Leuschner I, Schweiger MR, Savelyeva L, Watkins SC, Shao C, Bell E, Hofer T, Achter V, Lang U, Theissen J, Volland R, Saadati M, Eggert A, de Wilde B, Berthold F, Peng Z, Zhao C, Shi L, Ortmann M, Buttner R, Perner S, Hero B, Schramm A, Schulte JH, Herrmann C, O'Sullivan RJ, Westermann F, Thomas RK, Fischer M (2015) Telomerase activation by genomic rearrangements in highrisk neuroblastoma. Nature 526: 700-704. https://doi.org/10.1038/ nature14980

Peters JM, Nishivama T (2012) Sister chromatid cohesion. Cold Spring Harb Perspect Biol 4: a011130. https://doi.org/10.1101/cshperspect. a011130

Pugh TJ, Morozova O, Attiyeh EF, Asgharzadeh S, Wei JS, Auclair D, Carter SL, Cibulskis K, Hanna M, Kiezun A, Kim J, Lawrence MS, Lichenstein L, McKenna A, Pedamallu CS, Ramos AH, Shefler E, Sivachenko A, Sougnez C, Stewart C, Ally A, Birol I, Chiu R, Corbett RD, Hirst M, Jackman SD, Kamoh B, Khodabakshi AH, Krzywinski M, Lo A, Moore RA, Mungall KL, Qian J, Tam A, Thiessen N, Zhao YJ, Cole KA, Diamond M, Diskin SJ, Mosse YP, Wood AC, Ji LY, Sposto R, Badgett T, London WB, Moyer Y, Gastier-Foster JM, Smith MA, Auvil JMG, Gerhard DS, Hogarty MD, Jones SJM, Lander ES, Gabriel SB, Getz G, Seeger RC, Khan J, Marra MA, Meyerson M, Maris JM (2013) The genetic landscape of high-risk neuroblastoma. Nature Genetics 45: 279-284. https://doi. org/10.1038/ng.2529

Ray Chaudhuri A, Nussenzweig A (2017) The multifaceted roles of PARP1 in DNA repair and chromatin remodelling. Nat Rev Mol Cell Biol 18: 610-621. https://doi.org/10.1038/nrm.2017.53

Richman SA, Nunez-Cruz S, Moghimi B, Li LZ, Gershenson ZT, Mourelatos Z, Barrett DM, Grupp SA, Milone MC (2018) Highaffinity GD2-specific CAR T cells induce fatal encephalitis in a preclinical neuroblastoma model. Cancer Immunol Res 6: 36-46. https:// doi.org/10.1158/2326-6066.CIR-17-0211

Ruchaud S, Carmena M, Earnshaw WC (2007) Chromosomal passengers: conducting cell division. Nat Rev Mol Cell Biol 8: 798-812. https://doi.org/10.1038/nrm2257

Sahu D, Hsu CL, Lin CC, Yang TW, Hsu WM, Ho SY, Juan HF, Huang HC (2016) Co-expression analysis identifies long noncoding RNA SNHG1 as a novel predictor for event-free survival in neuroblastoma. Oncotarget 7: 58022-58037. https://doi.org/10.18632/ oncotarget.11158

Schmitt AM and Chang HY (2016) Long Noncoding RNAs in Cancer Pathways. Cancer Cell 29: 452-463. https://doi.org/10.1016/j. ccell.2016.03.010

Sun Y, Wang J, Pan S, Yang T, Sun X, Wang Y, Shi X, Zhao X, Guo J, Zhang X (2018) LINC00657 played oncogenic roles in esophageal squamous cell carcinoma by targeting miR-615-3p and JunB. Biomed Pharmacother 108: 316-324. https://doi.org/10.1016/j.biopha.2018.09.003

Tang W, Dong K, Li K, Dong R, Zheng S (2016) MEG3, HCN3 and linc01105 influence the proliferation and apoptosis of neuroblastoma cells via the HIF-1alpha and p53 pathways. Sci Rep 6: 36268. https://doi.org/10.1038/srep36268

Tichon A, Gil N, Lubelsky Y, Havkin Solomon T, Lemze D, Itzkovitz S, Stern-Ginossar N, Ulitsky I (2016) A conserved abundant cytoplasmic long noncoding RNA modulates repression by $\mathrm{Pu}-$ milio proteins in human cells. Nat Commun 7: 12209. https://doi. org/10.1038/ncomms12209

Ulitsky I, Bartel DP (2013) lincRNAs: genomics, evolution, and mechanisms. Cell 154: 26-46. https://doi.org/10.1016/j.cell.2013.06.020

Uryga A, Gray K, Bennett M (2016) DNA Damage and Repair in Vascular Disease. Annu Rev Physiol 78: 45-66. https://doi.org/10.1146/ annurev-physiol-021115-105127

Ventura A (2016) NORAD: Defender of the Genome. Trends Genet 32: 390-392. https://doi.org/10.1016/j.tig.2016.04.002

Wang C, Gong B, Bushel PR, Thierry-Mieg J, Thierry-Mieg D, Xu J, Fang H, Hong H, Shen J, Su Z, Meehan J, Li X, Yang L, Li H, Labaj PP, Kreil DP, Megherbi D, Gaj S, Caiment F, van Delft J, Kleinjans J, Scherer A, Devanarayan V, Wang J, Yang Y, Qian HR, Lancashire LJ, Bessarabova M, Nikolsky Y, Furlanello C, Chierici M, Albanese D, Jurman G, Riccadonna S, Filosi M, Visintainer 
R, Zhang KK, Li J, Hsieh JH, Svoboda DL, Fuscoe JC, Deng Y, Shi L, Paules RS, Auerbach SS, Tong W (2014) The concordance between RNA-seq and microarray data depends on chemical treatment and transcript abundance. Nat Biotechnol 32: 926-932. https:// doi.org/10.1038/nbt.3001

Wang L, Du L, Duan W, Yan S, Xie Y, Wang C (2018) Overexpression of long noncoding RNA NORAD in colorectal cancer associates with tumor progression. Onco Targets Ther 11: 6757-6766. https://doi.org/10.2147/OT'T.S176354

Wei H, Yu X (2016) Functions of PARylation in DNA Damage Repair Pathways. Genomics Proteomics Bioinformatics 14: 131-139. https://doi. org/10.1016/j.gpb.2016.05.001
Yu Y, Chen F, Yang Y, Jin Y, Shi J, Han S, Chu P, Lu J, Tai J, Wang S, Yang W, Wang H, Guo Y, Ni X (2019) lncRNA SNHG16 is associated with proliferation and poor prognosis of pediatric neuroblastoma. Int J Oncol 55: 93-102. https://doi.org/10.3892/ iio.2019.4813

Yu Y, Zhang J, Jin Y, Yang Y, Shi J, Chen F, Han S, Chu P, Lu J, Wang H, Guo Y, Ni X (2018) MiR-20a-5p suppresses tumor proliferation by targeting autophagy-related gene 7 in neuroblastoma. Cancer Cell Int 18: 5. https://doi.org/10.1186/s12935-017-0499-2 